\title{
The effect of A. Fumigatus SK1 and trichoderma sp. on the biogas production from cow manure
}

\author{
Zulfah Binti Zulkifli a, Nazaitulshila Binti Rasit a, Noor Azrimi Umor b, Shahrul Ismail a, ${ }^{*}$ \\ a School of Ocean Engineering, University Malaysia Terengganu, 21030 Kuala Terengganu, Terengganu, Malaysia \\ b School of Biology, Universiti Teknologi MARA (UiTM) Negeri Sembilan, Kampus Kuala Pilah, Pekan Parit Tinggi, 72000 Kuala Pilah, Negeri \\ Sembilan, Malaysia \\ * Corresponding author: shahrul.ismail@umt.edu.my
}

\section{Article history}

Received 27 February 2018

Revised 28 Mac 2018

Accepted 21 May 2018

Published Online 3 September 2018

\begin{abstract}
Lignocellulosic material consists of lignin, cellulose and hemicellulose. Converting lignocellulosic biomass such as cow manure $(\mathrm{CM})$ into value-added products provides a potential alternative. Hydrolysis of cellulose and hemicellulose is a limiting step during Anaerobic Digestion (AD) of lignocellulosic biomass. Lignin in lignocellulosic biomass is the barrier for hydrolysis, thus limits the biogas production. In this study, the effect of A.Fumigatus SK1 and Trichoderma sp. on enzymatic pretreatment of $\mathrm{CM}$ was investigated with respect to the biogas production. Three set of anaerobic digestion assays were carried out, with a working volume of $500 \mathrm{~mL}$ at $35 \pm 2^{\circ} \mathrm{C}$ and $120 \mathrm{rpm}$. The first set of fermentation contained untreated CM. The second set of fermentation involved addition of A.Fumigatus SK1, and the last set contained Trichoderma sp. Several analysis were conducted to determine the biomethane potential (BMP), anaerobic biodegradability, reducing sugars concentration and lignin removal of CM before and after pre-treatment. Result showed that, among both evaluated pre-treatment methods, CM treated with Trichoderma sp. gave the highest methane potential with $0.023 \mathrm{LCH}_{4}$-STP g VS${ }^{-1}$ compared to CM treated with A.Fumigatus SK1 $\left(0.011 \mathrm{LCH}_{4}-\mathrm{STP} \mathrm{g} \mathrm{VS}^{-1}\right)$. A good correlation have been found in this study between lignin removal and reducing sugar produced where, the total lignin removal after treated with Trichoderma sp. was $60 \%$ followed by $43 \%$ after treated with A.Fumigatus SK1.The reducing sugar produced after pre-treated with Trichoderma sp. and A.Fumigatus SK1 was about 9.59 and $4.91 \mu$ mol glucose, respectively. These results collectively suggested that CM treated with Trichoderma sp. could be a better pre-treatment method for the higher methane production in anaerobic mono-digestion process.
\end{abstract}

Keywords: Anaerobic mono-digestion, A. Fumigatus SK1, biogas; cow manure, trichoderma sp

(c) 2018 Penerbit UTM Press. All rights reserved

\section{INTRODUCTION}

Animal manure production is projected to increase further based on the trend of livestock population in 2011 until 2015 (Jabatan Perangkaan, 2015). Up until now, none proper manure disposal procedure has been done. Thus, requiring other alternatives to turn the manure into value-added products such as bioenergy. In Malaysia, about $329 \mathrm{kt} /$ year cow manure produced annually (Ghani, Mahmood \& Ali, 2013). In addition, the usage of animal manure for production of bioenergy can reduce odour and greenhouse gas emission, as well as water pollution through leaching mechanism (Sutaryo, 2012).

Dairy cows are normally fed with grasses which have high concentration of lignin complex with cellulose in the organic matter (S. Sutaryo, Ward \& Moller, 2014). Cellulose is the main component of lignocellulose, which is coated with hemicellulose and protected by lignin on the outer layer. It is a linear polymer comprising of $\beta(1 \rightarrow 4)$ linked D-glucose units. Hemicelluloses are branched polymers, whereas lignin are cross-linked macromolecules composed of phenylpropanoid unit (Matthews, 2016). Table 1 shows the compositions of cellulose, hemicellulose and lignin in cow manure (CM) from different previous studies.
Table 1 The compositions of cellulose, hemicellulose and lignin in cow manure (CM) from different previous studies.

\begin{tabular}{|c|c|c|c|}
\hline $\begin{array}{c}\text { Cellulose } \\
(\%)\end{array}$ & $\begin{array}{c}\text { Hemicellulose } \\
(\%)\end{array}$ & $\begin{array}{l}\text { Lignin } \\
(\%)\end{array}$ & References \\
\hline $1.6-4.7$ & $1.4-3.3$ & $2.7-5.7$ & $\begin{array}{l}\text { (K. Li, Liu, \& Sun, 2015) } \\
\text { (Parveen Kumar, Diane }\end{array}$ \\
\hline 26.59 & 11.27 & 11.24 & $\begin{array}{l}\text { M. Barrett, Michael J. } \\
\text { Delwiche, \& Stroeve, } \\
\text { 2009) }\end{array}$ \\
\hline 23.51 & 12.82 & 7.95 & $\begin{array}{l}\text { (Liao, Liu, Liu, Wen, \& } \\
\text { Chen, 2006) }\end{array}$ \\
\hline 21.89 & 12.47 & 13.91 & $\begin{array}{l}\text { (Wen, Liao, \& Chen, } \\
\text { 2004) }\end{array}$ \\
\hline
\end{tabular}

In Anaerobic Digestion (AD) of lignocellulosic biomass, hydrolysis of cellulose and hemicellulose is known as rate limiting step (Hu, Yue \& Liu, 2010). Cellulose and hemicellulose are hydrolysed into polysaccharide and monosaccharide by cellulolytic microorganisms (Hu et al., 2010; Mtui, 2009; Muthangya, Mshandete \& Kivaisi, 2009). While lignin, which composed of phenylpropanoid units act as barrier for hydrolysis which limit the biogas production $(\mathrm{K}$. 
Li et al., 2015; Matthews, 2016; Wi et al., 2015; Zheng, Zhao, Xu \& $\mathrm{Li}, 2014)$. There are numbers of developing technologies introduced with aimed to enhance the hydrolysis process by removing the lignin and hemicellulose, reducing the cellulose fibres crystallinity and increasing the accessible surface area of the biomass materials (Brodeur et al., 2011; Parveen Kumar et al., 2009; Taherzadeh \& Karimi, 2008). Among all, the physical or physicochemical is found to be the most efficient pre-treatment process to break down the lignocellulosic biomass. However, the method is less practical due to higher cost demand (Brodeur et al., 2011; Hu et al., 2010).

Biological pre-treatment offers another alternative. The most commonly used methods are acid hydrolysis and enzymatic hydrolysis. Diluted-acid hydrolysis process is a harsh process that lead to the formation of toxic degradation products (Taherzadeh \& Karimi, 2008). Compared to acid hydrolysis process, enzymatic hydrolysis process offer some advantages such as mild reaction condition, environmental friendly and lead to high yield of pure glucose (Saritha, Arora \& Lata, 2012; Wen et al., 2004). Hence, enzymatic hydrolysis offers a better option.

Enzymatic hydrolysis was found to increase the biogas production with the presence of fungi (Isroi et al., 2011; Vasmara, Cianchetta, Marchetti \& Galletti, 2015). Based on study reported by Mtui (2009), the lignocellulosic waste that has been pre-treated with fungi through anaerobic process has led to higher biogas production. Aspergillus sp. and Trichoderma sp. have been reported that these species are strongly cellulolytic (Adegunloye, et al., 2007). Trichoderma sp. has been proven to play an important role in lignin degradation (Saratale, Chien \& Chang, 2010). Recent studies revealed that Aspergillus fumigatus SK1 have an excellent ability to degrade untreated oil palm trunk (OPT) and Trichoderma reesei have the capability to produce enzyme (Ang, Yahya, Aziz \& Salleh, 2015). Besides, significant reduction in lignin and cellulose contents was observed in paddy straw inoculated with Aspergillus fumigatus, Aspergillus oryzae and Rhizopus oryzae (Viji \& Neelanarayanan, 2015). Other research has shown that Trichoderma reesei and Aspergillus niger are capable to degrade lignin and other recalcitrant organic compound (Fang, 2010). Based on study on sisal leaf done by (Muthangya et al., 2009), about 30-101\% increment in methane yield has been observed by applying two-stages fungal pretreatment, CCHT-1 fungi followed by Trichoderma reesei prior to AD. Also, up to $75 \%$ and $80 \%$ holocellulose and lignin degradation, respectively, have been achieved in the pre-treatment of lignocellulosic waste by using Aspergillus terreus and Trichoderma spp. (Mtui, 2009).

Many studies have been done on enzymatic hydrolysis using other substrates such as cassava bagasse (Gaewchingduang \& Pengthemkeerati, 2010); rice straw (Matthews, 2016; Viji \& Neelanarayanan, 2015); sugarcane bagasse (Batalha et al., 2015); oil palm trunk (Ang, et al., 2013); lemongrass leaves (Ang et al., 2015) and other lignocellulosic wastes (Mtui, 2009). However, limited attention has been paid on hydrolysing of animal manure especially CM. Therefore, the aim of this work is to investigate the effectiveness of enzymatic hydrolysis through A.Fumigatus SK1 and Trichoderma sp. on CM. The focus are to study the influence of lignin removal on reducing sugar and to improve the biogas production.

\section{MATERIALS AND METHODS}

\section{Substrate and anaerobic digestion inoculum}

In this study, CM has been used as substrate and it was collected from a cattle farm near Universiti Malaysia Terengganu, Malaysia. The $\mathrm{CM}$ was diluted with distilled water with 1:1 ratio (w/w) and blended to obtain homogenized substrate. Inoculum was collected from Palm Oil Mill Effluent (POME) in Serting, Negeri Sembilan, Malaysia. To avoid biological decomposition, the $\mathrm{CM}$ and inoculum was kept $4^{\circ} \mathrm{C}$. The homogenized sample were used to determine the chemical compositions of the substrate and inoculum used throughout the study, as shown in Table 2 .

\section{Fungi Preparation}

The fungi used in this study were A.Fumigatus SK1 and Trichoderma sp. A.Fumigatus SK1, which was locally isolated from UiTM Kuala Pilah and previously identified using 18S rNA characterization (Umor et al., 2016).Whereas, Trichoderma sp. was sampling at Setiu Wetlands, Kuala Terengganu. The spores were harvested after 7 days of incubation by using $1 \%$ v/v sterile Tween- 80 solution. Each plate that contained spores are diluted with $10 \mathrm{ml}$ of Tween-80 solution. Then, the spores were scrapped using sterile hockey stick. All the harvested spores were collected into one conical flask, diluted and used as spore suspension of $10^{8}$ spores/g of CM as described in (Ang et al., 2013).

\section{Biomethane potential assay}

Three set of experiments were employed for the biomethane potential evaluation. The first set of fermentation contained untreated $\mathrm{CM}$. The second set of fermentation involved addition of A.Fumigatus SK1, and the last set contained Trichoderma sp. The experiments were done in duplicate. The anaerobic digestion assay was carried out using $1000 \mathrm{~mL}$ Oxitop ${ }^{\circledR}$ bottles with a working volume of $500 \mathrm{~mL}$, at the temperature of $35 \pm 2{ }^{\circ} \mathrm{C}$. To initiate enzymatic hydrolysis, $10 \%$ (by volume) of A.Fumigatus SK1 and Trichoderma sp. were used to inoculate $167 \mathrm{ml}$ of CM. The corresponding substrate-to-inoculum ratio (S/I) was 0.5 , on a VS basis. Reducing sugar concentration and $\mathrm{pH}$ were determined at day 10 and was compared with controls which contain only the substrate (without adding any fungi). After day-10, the inoculum from POME was added in the bottles, tightly sealed, incubated and shaken at $130 \mathrm{rpm}$. Biogas production was monitored using an Oxitop ${ }^{\circledR}$ control 6, WTW. Equation (1) was used to obtain the BMP value for each pre-treatment as follow (Pereira, 2009):

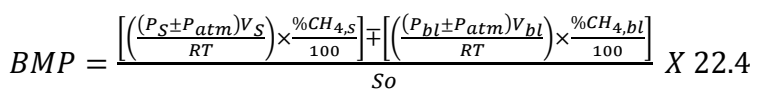

Where $\mathrm{P}_{\mathrm{S}}$ is the pressure in sample bottle $(\mathrm{Pa}), \mathrm{P}_{\mathrm{bl}}$ is the pressure in blank bottle $(\mathrm{Pa}), \mathrm{P}_{\mathrm{atm}}$ is the atmospheric pressure $(\mathrm{Pa}), \mathrm{V}_{\mathrm{S}}$ is the headspace volume of the test bottle $\left(\mathrm{m}^{3}\right), \mathrm{V}_{\mathrm{bl}}$ is the headspace volume of the blank bottle $\left(\mathrm{m}^{3}\right), \% \mathrm{CH}_{4, \mathrm{~s}}$ is the percentage of methane in the test bottle, $\% \mathrm{CH}_{4, \mathrm{bl}}$ is the percentage of methane in the blank bottle, $\mathrm{R}$ is the universal gas constant $8.3314\left(\mathrm{~Pa} \mathrm{~m}^{3} \mathrm{~mol}^{-1} \mathrm{~K}^{-1}\right)$ and $\mathrm{So}$ is the amount of the substrate added (g VS).

\section{Measurement of sugar concentration}

After 10 days of fermentation, $1 \mathrm{~g}$ of $\mathrm{CM}$ was extracted and placed into the test tubes. Each test tube was added with $1 \mathrm{ml}$ of DNS reagent and 2 drops of $0.1 \mathrm{M} \mathrm{NaOH}$ and incubated at $50^{\circ} \mathrm{C}$ for 5 minutes. The tubes were added with $10 \mathrm{ml}$ of distilled water and inverted several times for homogenization through mixing. The reducing sugar released was determine as described in (Umor et al., 2016).

\section{Statistical Analysis}

In order to determine if there exist statistical significant difference among untreated and pre-treated CM, the data set is subjected with oneway analysis using ANOVA, adopting SPSS version 22. Probabilities of $\mathrm{P}<0.05$ are considered as significant.

\section{Analytical methods}

Characterization of the substrate and inoculum including Total Solids (TS) and Volatile Solids (VS) were performed based on standard methods (APHA, 2012). The Chemical Oxygen Demand (COD) was measured by a digestion colorimetric method (HACH Reactor Digestion Method 8000) using a HACH DR/2000 spectrophotometer. The $\mathrm{pH}$ before and after anaerobic digestion of the biomass effluents were determined using $\mathrm{pH}$ meter (Thermo-868, USA). Grinding The total fibers content were determined by the gravimetric methods (Goering \& Soest, 1970). The structural changes on CM fibre before and after pre-treatment were studied using Table Top Microscope (TM3030, Hitachi).

\section{RESULTS AND DISCUSSION}

\section{Chemical compositions of $\mathrm{CM}$ and inoculum}

Characteristics of $\mathrm{CM}$ and inoculum are shown in Table 2. VS contents of the raw $\mathrm{CM}$ were found to be in the range of 80.74 to $83.55 \%$ and 63.62 to $64.63 \%$ for inoculum. The result indicated that the 
substrate and inoculum used in this study were high in organic matter and have high potential to produce biogas (Chaikitkaew, Kongjan, \& O-Thong, 2015) (Chaikitkaew et al., 2015). The cellulose, hemicellulose and lignin contents of CM were $26 \%, 14 \%$ and $12 \%$, respectively. The comparison characteristics of $\mathrm{CM}$ used in recent studies are shown in Table 1, where the cellulose, hemicellulose and lignin content range from 1.6 to $26.6 \%, 1.4$ to $12.8 \%$ and 2.7 to $13.9 \%$, with average of 24.2, 12.1 and 11.0 respectively (K. Li et al., 2015; Liao et al., 2006; Parveen Kumar et al., 2009; Wen et al., 2004). The characteristics of the CM used in this study were in agreement to those reported in earlier studies.

Table 2 Characteristics of substrate and inoculum used in the experiment.

\begin{tabular}{llll}
\hline Parameter & Unit & CM & Inoculum \\
\hline TS & $\%$ & $6.47-7.81$ & $3.88-4.84$ \\
VS & $\%$ & $80.74-83.55$ & $63.62-64.63$ \\
VS/TS & - & 10.69 & 13.35 \\
COD & $\mathrm{mg} / \mathrm{mL}$ & $29,150-37,050$ & $4,217-5,112$ \\
pH & - & 6.23 & 6.92 \\
Total fibre & $\%$ & 52 & $\mathrm{ND}$ \\
Lignin & $\%$ & 12 & $\mathrm{ND}$ \\
Cellulose & $\%$ & 26 & $\mathrm{ND}$ \\
Hemicellulose & $\%$ & 14 & $\mathrm{ND}$ \\
\hline
\end{tabular}

*ND: Not detected

Biomethane potential and anaerobic biodegradability of different fungal pre-treatment

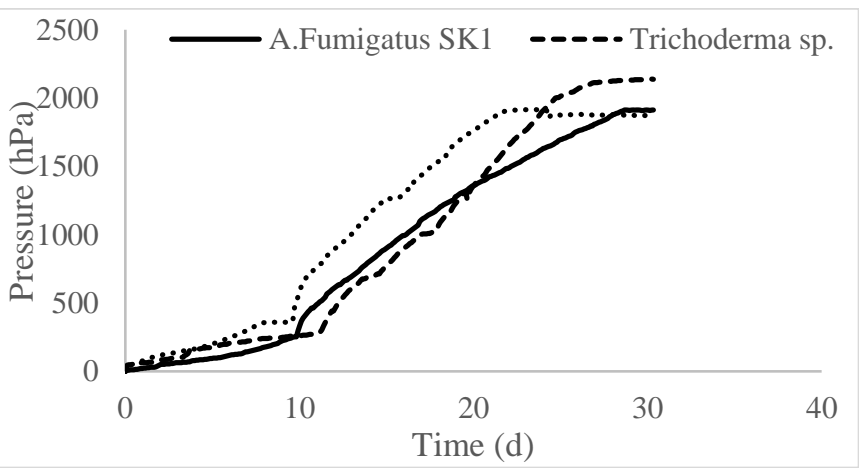

Fig. 1 Biogas production after 30 days of digestion during BMP assessment.

Fig. 1 illustrates the cumulative pressure increment produced during biomethane potential (BMP) assessment for CM pre-treated with A.Fumigatus SK1 and Trichoderma sp. in 30 days. The pressure produced in each pre-treatment was significantly higher with $(\mathrm{P}<0.05)$ than the untreated CM. The highest pressure in each pre-treatment was used to calculate the BMP after pre-treatment based on the equation (1). The values of BMP are vital in order to determine the effectiveness of

\section{Reducing sugar}

The main reducing sugars that will be produced in the processed lignocellulosic waste are glucose, xylose, xylitol, cellobiose, arabinose, pentose and galactose (Mtui, 2009). The data in Fig. 2 demonstrated the reducing sugar (glucose) produced from CM treated with A. Fumigatus SK1 and Trichoderma sp. for 10 days of fermentation. After day tenth, CM treated with Trichoderma sp. and CM treated with A. Fumigatus SK1 produced about $12.12 \mu \mathrm{mol}$ glucose and $11.77 \mu \mathrm{mol}$ glucose, respectively. Whereas, the untreated $\mathrm{CM}$ showed the lowest glucose produced which was about $8.56 \mu \mathrm{mol}$ glucose. To note, the reducing sugar released from CM degraded by biological pre-treatment. Meanwhile, the anaerobic biodegradability can be determined based on elemental compositions of the organic substrates using Buswell's equation as described previously by (Angelidaki \& Sanders, 2004). Table 3 shows the BMP and anaerobic biodegradability of CM pretreated with A.Fumigatus SK1 and Trichoderma sp. Highest methane potential of CM was achieved after pre-treated with Trichoderma sp. followed by CM pre-treated with A. Fumigatus SK1. The results were in accordance with the percentage biodegradability achieved for both pre-treatment. It is due to high availability of substrates to be digested by these anaerobic microorganisms (Muthangya et al., 2009). These findings was supported by previous research done by Meng et al. (2015), in which higher in biodegradability has contributed to the higher biomethane yield production.

Table 3 Biomethane potential (BMP) and biodegradability of CM pretreated with A.Fumigatus SK1 and Trichoderma sp.

\begin{tabular}{lccc} 
Type of pre-treatment & $\begin{array}{c}\text { Biomethane } \\
\text { potential } \\
\left(\mathbf{L C H}_{4}-\mathbf{S T P}\right. \\
\left.\mathbf{g ~ V S}^{-1}\right)\end{array}$ & $\begin{array}{c}\text { Theoretical } \\
\text { yield } \\
\left(\mathbf{L C H}_{\mathbf{4}}-\mathbf{S T P}\right. \\
\left.\mathbf{g ~ V S}^{-1}\right)\end{array}$ & $\begin{array}{c}\mathbf{B}_{\mathbf{d}} \\
(\%)\end{array}$ \\
\hline $\begin{array}{l}\text { CM pre-treated with } A . \\
\text { Fumigatus SK1 }\end{array}$ & 0.011 & 0.10 & 9 \\
$\begin{array}{l}\text { CM pre-treated with } \\
\text { Trichoderma sp. }\end{array}$ & 0.023 & 0.33 & 15 \\
\hline
\end{tabular}

$\left(B_{\mathrm{d}}\right)$ : Biodegradability.

\section{Composition and structure of pre-treated sample}

Methane gas can be produced by the anaerobic degradation process of organic components such as carbohydrate, proteins and lipids that present in CM. Based on Aslanzadeh, J.Taherzadeh, and Horvath (2011), the percentage of methane gas produced was influenced by the composition of fibre, cellulose, hemicellulose, protein, fat, starch and sugar content. Based on previous finding, (Singh et al., 2008) have found that reduction of lignin content in CM significantly depend on the action of different microorganism. As shown in Table 4, Trichoderma sp. recorded maximum lignin reduction in CM with $60 \%$, compared to $43 \%$ lignin removal after treated with A. Fumigatus SK1. Singh et al. (2008) have shown that Trichoderma citronoviridae capable to degrade the sugarcane straw up to $8 \%$. The result of delignification was in agreement with the biomethane potential obtained as discussed in section 3.2, where the increase in lignin degradation has contributed to higher biomethane potential. This result was supported by previous study done by (Y. Li et al., 2013) which stated that the lignin content in the substrate was a significant parameter affecting the methane production potential.

A. Fumigatus SK1 and Trichoderma sp. were higher than the untreated $\mathrm{CM}$. The result demonstrated that pre-treatment of CM using these two types of fungi may accelerate the hydrolysis process. The difference in sugar release level between two different fungi may be attributed to the differential level of cellulase and xylanase produced by different fungi (Kuhar, Nair \& Kuhad, 2008). The amount of reducing sugar produced was in accordance with the percentage of lignin degradation after each pre-treatment. CM pre-treated with Trichoderma sp. marked the highest lignin degradation of $60 \%$ followed by CM treated with A. Fumigatus SK1 and untreated CM with $43 \%$ and $42 \%$, respectively. The higher amount of reducing sugar pre-treated with Trichoderma sp. could be because of the maximum lignin degradation, which eventually increased the accessibility to enzymatic hydrolysis (Kuhar et al., 2008).

Table 4 Lignocellulosic alterations in microbial pre-treated CM.

\begin{tabular}{lcccc}
\hline \multicolumn{1}{c}{ Determination } & Unit & $\begin{array}{c}\text { Before Pre- } \\
\text { treatment }\end{array}$ & $\begin{array}{c}\text { Pre-treated with } \\
\text { Fumigatus SK1 }\end{array}$ & $\begin{array}{c}\text { A. } \\
\text { Pre-treated } \\
\text { Trichoderma sp. }\end{array}$ \\
\hline Neutral detergent fibres (NDF) & \% of dry weight & 73.90 & 64.05 & 77.22 \\
Acid detergent fibres (ADF) & \% of dry weight & 65.38 & 40.04 & 39.19 \\
Acid detergent lignin (ADF) & \% of dry weight & 52.39 & 29.88 & 21.20 \\
Hemicellulose & \% of dry weight & 8.52 & 24.01 & 38.03 \\
Cellulose & \% of dry weight & 12.99 & 5.87 & 17.98 \\
Lignin & \% of dry weight & 52.39 & 29.88 & 21.20 \\
\hline
\end{tabular}




\section{Structural changes of CM before and after pre-treatment}

The changes of physical structure of CM were observed using table top microscope. The images revealed the shapes and surface morphologies of the $\mathrm{CM}$, before and after pre-treatment.

Fig. 3B shows the image of raw CM. The structure of raw CM without pre-treatment was much rougher, flat and intact compared to the pre-treated manure (Chen et al., 2003). The changes of enzymatic hydrolysis of manure were presented in Fig. 3F. The surface of manure fiber was exposed and degraded partially. It was observed that the structure of the manure fiber become looser, which would facilitate the entrance and degradation for microorganisms and their hydrolases $(\mathrm{Xu}$, $\mathrm{Xu}, \mathrm{Liu}, \mathrm{Li}, \& \mathrm{Liu}, 2015)$. Moreover, the manure fiber was further destroyed where a number of small holes were observed, as presented in Fig. 3H. R. Li et al. (2009) reported that, the small holes in the manure fibres described that the part of hemicellulose was degraded from the backbone of the fibres. The structure of manure fibres after hydrolysis were shown as in Fig. 3E and 3G. Both were found thinner and shorter as compared to the raw manure fibers in Fig. 3A. This observation might be because of the pre-treatment process may has disrupts the linkage between lignin, hemicellulose and cellulose as well as decreasing the crystallinity of CM in order to create more accessible pore volume and specific surface area for cellulolysis and xylanolysis (Ang et al., 2013). Considering the relatively high glucose concentration and lignin degradation as discuss in section 3.3 and 3.4 which compared to the untreated manure, the main structure might be partially degraded (Chen et al., 2003). From the view point of tabletop microscopy, enzymatic pre-treatment could enhance the lignin degradation of CM (Xu et al., 2015). Thus, would enhance contribute to the improvement of methanogenesis process ( $\mathrm{R} . \mathrm{Li}$ et al., 2009)

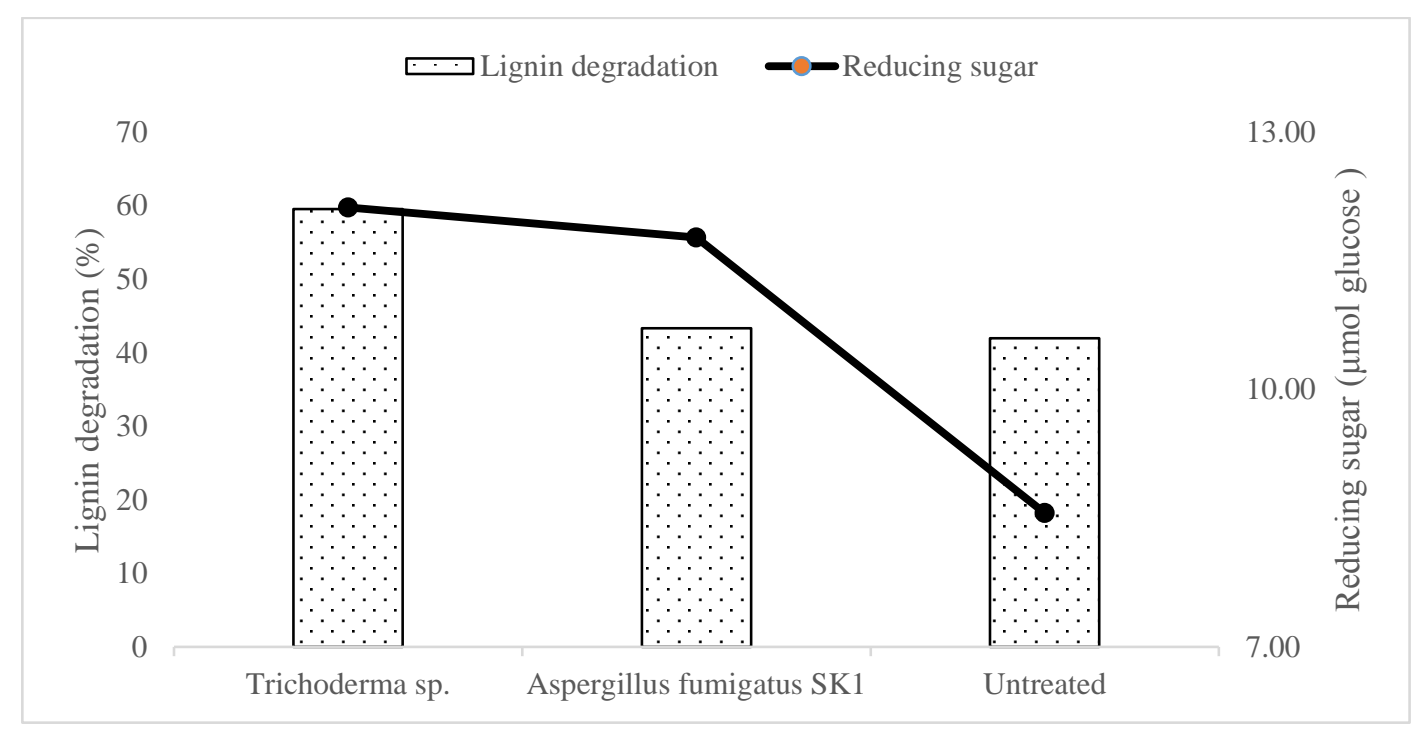

Fig. 2 Reducing sugars obtained and lignin degradation from CM treated with A.Fumigatus SK1 and Trichoderma sp.

Table 5: Lignocellulosic alterations in microbial pre-treated CM

\begin{tabular}{lcccc}
\hline \multicolumn{1}{c}{ Determination } & Unit & $\begin{array}{c}\text { Before Pre- } \\
\text { treatment }\end{array}$ & $\begin{array}{c}\text { Pre-treated with } \boldsymbol{A} \text {. } \\
\text { Fumigatus SK1 }\end{array}$ & $\begin{array}{c}\text { Pre-treated with } \\
\text { Trichoderma sp. }\end{array}$ \\
\hline Neutral detergent fibres (NDF) & \% of dry weight & 73.90 & 64.05 & 77.22 \\
Acid detergent fibres (ADF) & \% of dry weight & 65.38 & 40.04 & 39.19 \\
Acid detergent lignin (ADF) & \% of dry weight & 52.39 & 29.88 & 21.20 \\
Hemicellulose & \% of dry weight & 8.52 & 24.01 & 38.03 \\
Cellulose & \% of dry weight & 12.99 & 5.87 & 17.98 \\
Lignin & \% of dry weight & 52.39 & 29.88 & 21.20 \\
\hline
\end{tabular}

\section{Removal efficiency}

In anaerobic system, the digestion efficiency is closely related to the mass conversion. Mass consumption which would be presented by TS, VS reduction and COD changes would determine the production of biogas (Meng et al., 2015). In this study, the concentration of COD before and after pre-treatment as well as the COD removal have also been analysed. The results are presented in Fig. 4. The trend after 30 days of digestion illustrates that methanogenic bacteria consumed COD by fermentation process (Macias-Corral et al., 2008). Compared with the untreated $\mathrm{CM}$, the $\mathrm{CM}$ treated with fungi (Trichoderma sp. and A. Fumigatus SK1) showed better COD removal. CM treated with Trichoderma sp. marked about 53\% reduction in COD followed by CM treated with A. Fumigatus SK1 which was about $41 \%$. The results obtained were similar to the Budiyono, et al., (2014) that the more COD were removed, the more biogas were produced. 


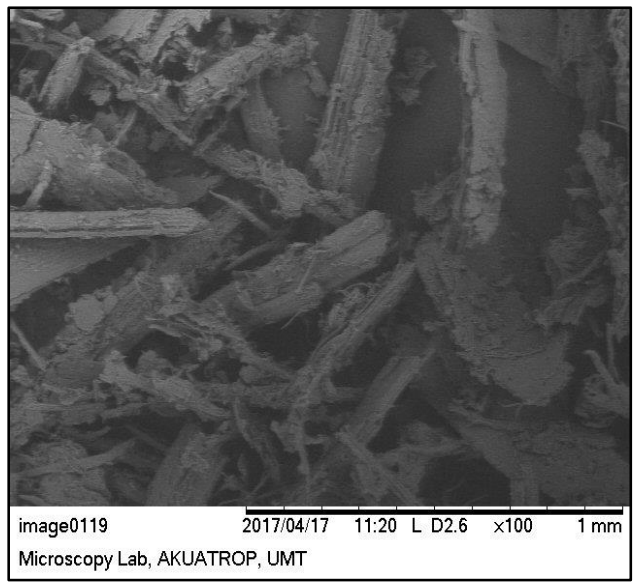

A

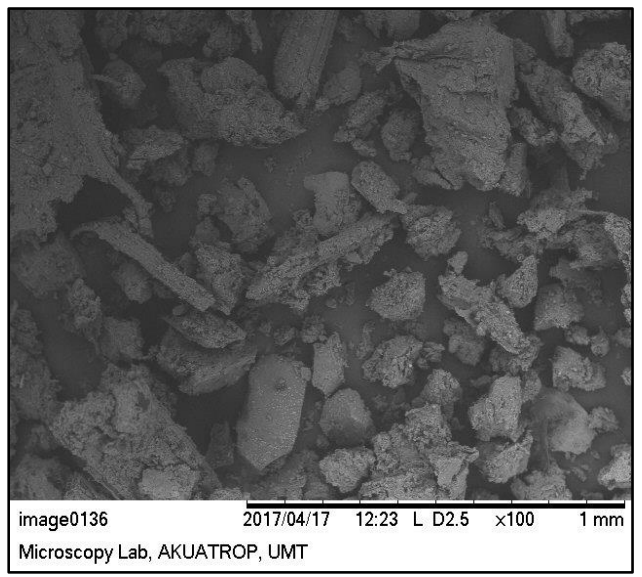

$\mathrm{C}$
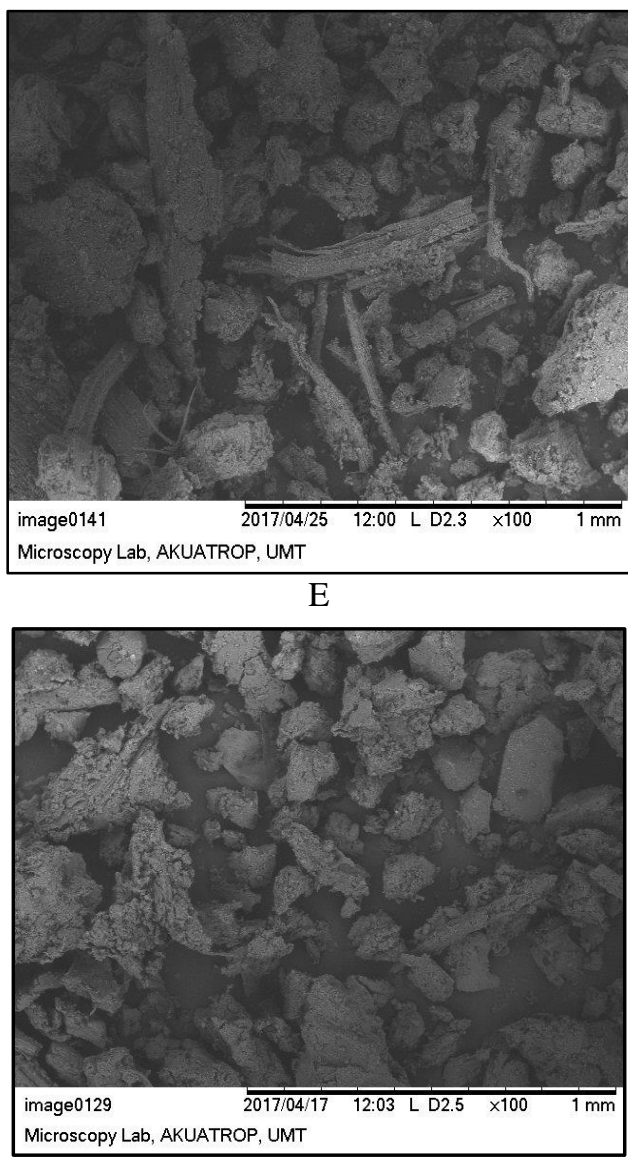

G

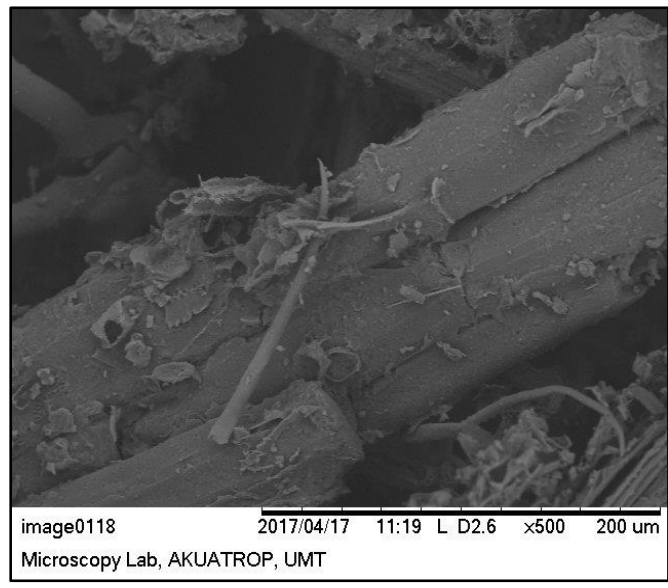

B

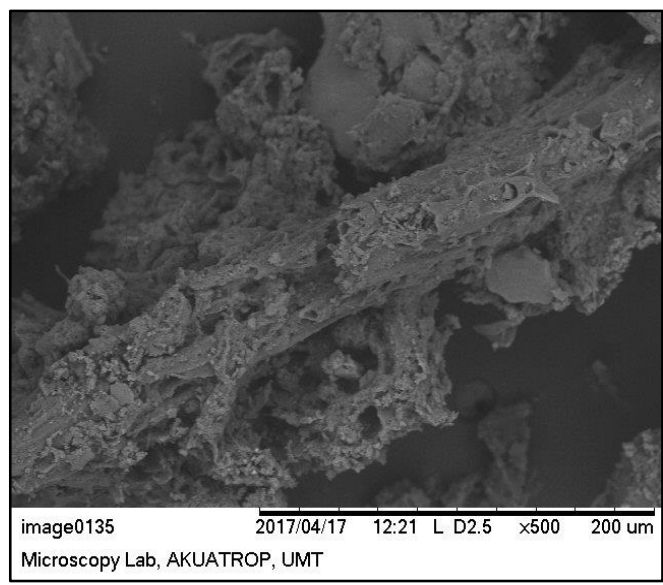

$\mathrm{D}$

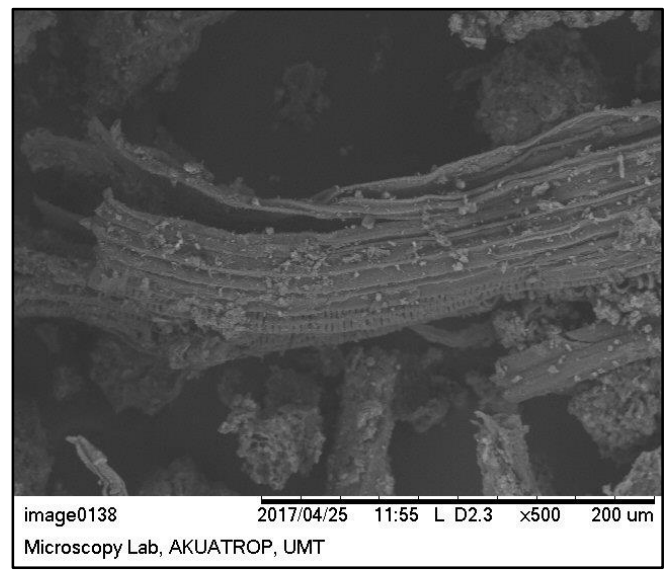

$\mathrm{F}$

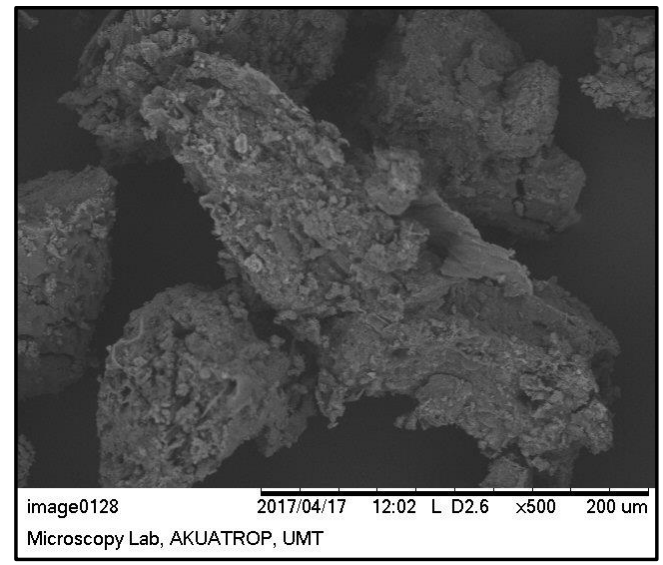

$\mathrm{H}$

Fig. 3 Table top microscope images of CM. (A) Raw CM; (B) Raw CM (500x); (C) Untreated CM; (D) Untreated CM (500X); (E) CM with addition of A. Fumigatus SK1; (F) CM with addition of A. Fumigatus SK1(500X); (G) CM with addition of Trichoderma sp.; (H) CM with addition of Trichoderma sp. (500x). 


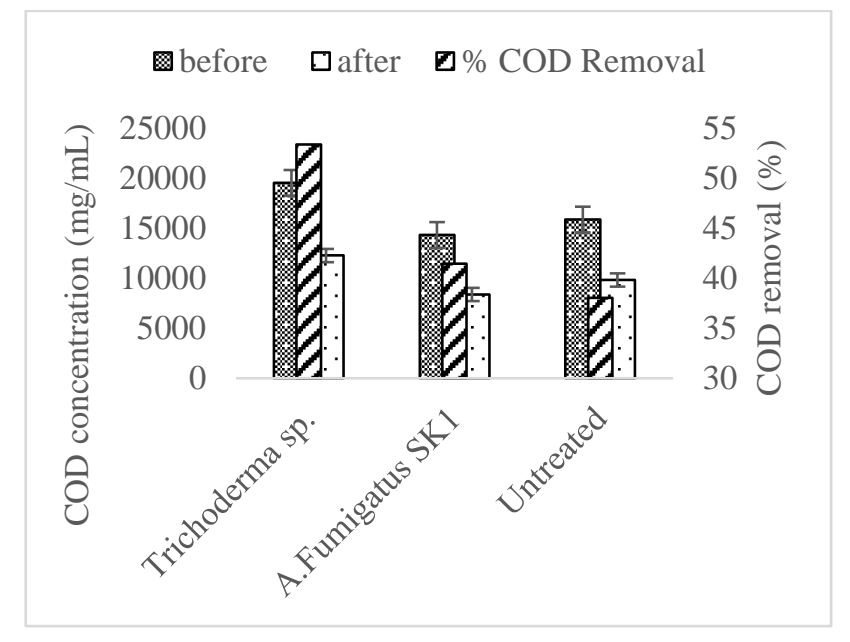

Fig. 4 COD removal during 30 days of fermentation.

\section{CONCLUSION}

This study revealed that there was a good correlation between biodegradability and lignin content of $\mathrm{CM}$ to the biogas production potential. From both biological pre-treatment conducted using two different species of fungi, CM pre-treated with Trichoderma sp. showed the highest biodegradability and lowest total lignin content. Thus, it contributes to the highest biogas production potential. From our best understanding, CM pre-treated with Trichoderma sp. is suggested as the best method for mono-digestion of CM.

\section{ACKNOWLEDGEMENT}

This research work is supported by the Project Research Acculturation Grant Scheme (RAGS) (Vote No 57083) supported by Ministry of Education Malaysia

\section{REFERENCES}

Adegunloye, D. V., Adetuyi, F. C., Akinyosoye, F. A., Doyeni, M. O. 2007. Microbial analysis of compost using cowdung as booster. Pakistan Journal of Nutrition, 6, 5, 506 - 510.

Ang, S. K., Shaza, E. M., Adibah, Y., Suraini, A. A., Madihah, M. S. 2013. Production of cellulases and xylanase by aspergillus fumigatus sk1 using untreated oil palm trunk through solid state fermentation. Process Biochemistry, 48, 1293-1302.

Ang, S. K., Yahya, A., Aziz, S. A., Salleh, M. M. 2015. Isolation, screeening, and identification of potential cellulolytic and xylanolytic producers for biodegradation of untreated oil palm trunk and its application in saccharification of lemongrass leaves. Taylor \& Francis, 45, 279 - 305.

Angelidaki, I., Sanders, W. 2004. Assessment of the anaerobic biodegradability of macropollutants. Environmental Science and Bio/Technology, 3, 117-129.

American Public Health Association (APHA). 2012. Standard methods for the examination of water and wastewater. In A. D. Eaton, L. S. Clesceri, Rice, E.W., A. E. Greenberg, Franson, M.A.H ( $22^{\text {nd }}$ Eds.). Washington, D.C., USA: APHA.

Aslanzadeh, S., Taherzadeh, M. J., Horvath, I. S. 2011. Pretreatment of straw fraction of manure for improved biogas production. Bioresource Technology, 6(4),5193-5205.

Batalha, L. A. R., Han, Q., Jameel, H., Chang, H.-m., Colodette, J. L., Gomes, F. J. B. 2015. Production of fermentable sugars from sugarcane bagasse by enzymatic hydrolysis after autohydrolysis and mechanical refining. Bioresource Technology, 180, 97-105.

Brodeur, G., Yau, E., Badal, K., Collier, J., Ramachandran, K. B., Ramakrishnan, S. 2011. Chemical and physicochemical pretreatment of lignocellulosic biomass: A review. Enzyme Research, 2011, 1-17.

Budiyono, I.Syaichurrozi, S.Sumardiono. 2014. Effect of total solid content to biogas production rate from vinasse. International Journal of Engineering, 27(2), 177-184.

Chaikitkaew, S., Kongjan, P., O-Thong, S. 2015. Biogas production from biomass residues of palm oil mill by solid state anaerobic digestion. Energy Procedia, 79, 838-844.

Chen, S., Liao, W., Liu, C., Wen, Z., Kincaid, R. L., Harrison, J. H. 2003. Valueadded chemicals from animal manure. Retrieved from
https://www.pnnl.gov/main/publications/external/technical_reports/PNNL14495.pdf

Fang, H. H. P. 2010. Environmental Anaerobic Technology. London: Imperial Collage Press.

Gaewchingduang, S., Pengthemkeerati, P. 2010. Enhancing efficiency for reducing sugar from cassava bagasse by pretreatment. International Journal of Environmental, Chemical, Ecological, Geological and Geophysical Engineering, 4(10), 477-480.

Ghani, L. A., Mahmood, N. Z., Ali, N. A. 2013. Biomass energy flow assessment using the material flow analysis (MFA) method for livestock production system. World Applied Sciences Journal, 27(8), 961-969.

Goering, H. K., Soest, P. J. V. 1970. Forage fibre analysis (apparatus, reagents, procedures and some applications). In Agricultural Handbook no. 379. Agricultural Research Service, Washington, DC: United States Department of Agriculture.

Hu, Z. H., Yue, Z.-B., Liu, S.-Y. 2010. Anaerobic digestion of lignocellulosic wastes by rumen microorganisms: Chemical and Kinetic Analyses. London: Imperial Collage Press.

Isroi, Millati, R., Syamsiah, S., Niklasson, C., Cahyanto, M. N., Lundquist, K., et al. 2011. Biological pretreatment of lignocelluloses with white-rot fungi and its applications: A review. Bio Resources, 6(4), 5224-5259.

Kuhar, S., Nair, L. M., Kuhad, R. C. 2008. Pretreatment of lignocellulosic material with fungi capable of higher lignin degradation and lower carbohydrate degradation improves substrate acid hydrolysis and the eventual conversion to ethanol. Canadian Journal of Microbiology, 54, 305-313.

Li, K., Liu, R., Sun, C. 2015. Comparison of anaerobic digestion characteristics and kinetics of four livestock manures with different substrate concentrations. Bioresource Technology, 198, 133-140.

Li, R., Chen, S., Li, X., Lar, J. S., He, Y., Zhu, B. 2009. Anaerobic codigestion of kitchen waste with cattle manure for biogas production. Energy \& Fuels, 23(4), 2225-2228.

Li, Y., Zhang, R., Liu, X., Chen, C., Xiao, X., Feng, L., et al. 2013. Evaluating methane production from anaerobic mono- and co-digestion of kitchen waste, corn stover, and chicken manure. American Chemical Society, 27, 2085-2091.

Liao, W., Liu, Y., Liu, C., Wen, Z., Chen, S. 2006. Acid hydrolysis of fibers from dairy manure. Bioresource Technology, 1687-1695.

Macias-Corral, M., Samani, Z., Hanson, A., Smith, G., Funk, P., Yu, H., et al. 2008. Anaerobic digestion of municipal solid waste and agricultural waste and the effect of co-digestion with dairy cow manure. Bioresource Technology, 99, 8288-8293.

Matthews, S. 2016. Structural changes of rice straw pre-treated with paenibacillus and aspergillus fumigatus. International Journal of Agricultural and Food Research, 5(4), 1-8.

Meng, Y., Li, S., Yuan, H., Zou, D., Liu, Y., Zhu, B., et al. 2015. Evaluating biomethane production from anaerobic mono- and co-digestion of food waste and floatable oil (fo) skimmed from food waste. Bioresource Technology, 185, 7-13.

Mtui, G. Y. S. 2009. Recent advances in pretreatment of lignocellulosic wastes and production of value added products. African Journal of Biotechnology, 8(8), 1398 - 1415.

Muthangya, M., Mshandete, A. M., Kivaisi, A. K. 2009. Two-stage fungal pretreatment for improved biogas production frim sisal leaf decortication residues. International Journal of Molecular Sciences, 10, 4805-4815.

Kumar, P., Barrett, D.M., Delwiche, M. J., Stroeve, P. 2009. Methods for pretreatment of lignocellulosic biomass for efficient hydrolysis and biofuel production. Industrial \& Engineering Chemistry Research, 48(8), 3713-3729.

Pereira, C. P. P. 2009. Anaerobic Digestion in sustainable Biomass Chains. (Doctoral dissertation), Wageningen University, Wageningen. (978-90-8585432-6).

Saratale, G. D., Chien, L.-J., Chang, J. S. 2010. Enzymatic Treatment of Lignocellulosic Wastes for Anaerobic Digestion and Bioenergy Production. London: Imperial Collage Press.

Saritha, M., Arora, A., Lata. 2012. Biological pretreatment of lignocellulosic substrates for enhanced delignification and enzymatic digestibility. Indian Journal of Microbiology, 52(2), 122-130.

Singh, P., Suman, A., Tiwari, P., Arya, N., Gaur, A., Shrivastava, A. K. 2008. Biological pretreatment of sugarcane trash for its conversion to fermentable sugars. World Journal of Microbiology and Biotechnology, 24, 667-673.

Sutaryo. 2012. Optimisation and inhibition of anaerobic digestion of livestock manure. PhD Thesis, Department of Engineering, AU Foulum. Blichers Allé 20.

Sutaryo, S., Ward, A. J., Moller, H. B. 2014. The effect of mixed-enzyme addition in anaerobic digestion on methane yield of dairy cattle manure. Taylor \& Francis, 35, 2476-2482.

Taherzadeh, M. J., Karimi, K. 2008. Pretreatment of lignocellulosic wastes to improve ethanol and biogas production: A review. International Journal of Molecular Sciences, 9(9), 1621-1651.

Umor, N. A., Azmi, M., Jamroo, N. A., Khalil, K., Muhammad, S. A. F. S., Mahmood, N. A. N. 2016. Bioconversion of oil palm frond to reducing sugar 
in solid state fermentation by applying water-fed strategy. Journal of Engineering and Applied Science, 11(9), 1916-1920.

Vasmara, C., Cianchetta, S., Marchetti, R., Galletti, S. 2015. Biogas production from wheat straw pre-treated with ligninolytic fungi and co-digestion with pig slurry. Environmental Engineering and Management Journal, 14(7), 17511760

Jabatan Perangkaan. 2015. Perangkaan Ternakan Malaysia, Jabatan Perangkaan Veterinar, Malaysia.

Viji, J., Neelanarayanan, P. 2015. Efficacy of lignocellulolytic fungi on the biodegradation of paddy straw. International Journal of Environmental Research, 9(1), 225 - 232.

Wen, Z., Liao, W., Chen, S. 2004. Hydrolysis of animal manure lignocellulosics for reducing sugar production. Bioresource Technology, 91, 31-39.
Wi, S. G., Cho, E. J., Lee, D.-S., Lee, S. J., Lee, Y. J., Bae, H.-J. 2015. Lignocellulose conversion for biofuel: A new pretreatment greatly improves downstream biocatalytic hydrolysis of various lignocellulosic materials. Biotechnology for Biofuels, 8, 228-238.

Xu, J., Xu, X., Liu, Y., Li, H., Liu, H. 2015. Effect of microbiological inoculants $\mathrm{dn}-1$ on lignocellulose degradation during co-composting of cattle manure with rice straw monitored by ftir and sem. American Institute of Chemical Engineers, 35(2) 345-351.

Zheng, Y., Zhao, J., Xu, F., Li, Y. 2014. Pretreatment of lignocellulosic biomass for enhanced biogas production. Progress in Energy and Combustion Science, $42,35-53$. 